\begin{tabular}{|c|c|}
\hline \multirow{3}{*}{ 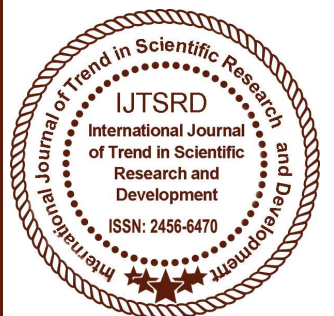 } & $\begin{array}{l}\text { International Journal of Trend in Scientific } \\
\text { Research and Development (IJTSRD) }\end{array}$ \\
\hline & International Open Access Journal \\
\hline & ISSN No: 2456 - 6470 | www.ijtsrd.com | Volume - 2 | Issue - 2 \\
\hline
\end{tabular}

\title{
Impact of Conflict Management on the Efficiency and Effectiveness of Business
}

\author{
Dr. E. M. Chukwuma \\ School of Business Studies \\ Business Administration and Management, \\ Federal Polytechnic, Oko
}

\section{ABSTRACT}

This paper examines the classifications, cause; types and the possible solutions of conflict in organization. This discovered that conflict generates considerable ambivalence and leave many practitioners and scholars quite uncertain about how best to cope with it. Conflicts are inevitable in human life and also inevitable in organizations even between countries. Conflict occurs in organizations as a result of competition for supremacy, scarcity of economic resource and leadership style. The study also revealed that conflict in organization could be constructive or destructive which can lead to low production or good solution to production.

\section{INTRODUCTION}

Ordinarily Conflict means a serious disagreement or argument, typically a protracted one. It might mean an incompatible or at variance clash. While conflict management is the process of limiting the negative aspects of Conflict while increasing the positive aspect of conflict, the aim of conflict management is to enhance learning and group outcomes, including effectiveness of performance in organizational settling (Rahim, 2002).

Conflict is an inevitable element of any labourmanagement relationship. In any work situation people are bound to have different interests and aspirations which may tend to conflict with each other. Conflict is also imminent in any organization where people from different social-culture background have to interact in the collective efforts towards achieving a common goal. This is because in addition to the common workplace, employees carriers personal ambition they earnestly desires to achieve alongside the organizational goal. The individual goal or interest may not necessary be compatible with that of other member. Therefore, the end result is clash of interest. For example, most organizational management is committed to pursuing a goal of profit maximization or minimizing cost inputs through economic decision and policies. The workers, through their union want higher wages and lucrative welfare package which on the side of management will result to high cost of doing business. Management will not, but resist these unwholesome moves, in the process, conflict will ensure, therefore, it is obvious that conflict is inherent in every organization irrespective of size, mission or age.

To this end, organization, be it private or public are perceived to always assume that conflicts damage the relationship that exist within the work places. It is based on the forgoing that a study on measurement of conflicts effectiveness and efficiency became paramount as a subject of interest.

\section{THE CONCEPT OF CONFLICT}

One of the aims of any organization is to create an environment in which individuals and groups of people can cooperate with one another to achieve the organizational goals. Major problems in the 
organization is that individuals and work groups compete for limited resources, power, status, positions etc, to an extent that their competition leads to disruption of the organizations objectives. These competitions bad or good are generally referred as conflicts.

Schramm-Nielsen (2002) defines a Conflict-as a state of serious disagreement and argument about something perceived to be important by at least one of the parties involved. Obisi (1996) argues that despite this fact, peace forms one of the fundamental factors for enhanced productivity with resultant benefits to both the labour and management as well as for the economic development of the country. Therefore, it will not be out of place, to consider conflict as an inevitable and desirable factor in the work place. Azamosa (2004) observed that conflicts involve the total range of behaviours and attitudes that is in opposition between owners/managers on the one hand and working people on the other. It is a state of disagreement over issues of substance to emotional antagonism and may arise due to anger, mistrust or personality clash.

Conflicts exist whenever an action by one party is perceived as preventing or interfering with the goals, needs or actions of another party. Conflict can arise over a multiple or organizational experiences, such as incompatible goals, differences in the interpretation of facts, negative feelings, differences in values and philosophies, or disputes over share of resources. As define above, conflict tends to be associated with negative features and situations which give rise to inefficiency, ineffectiveness or dysfunctional consequences. But in some cases, it can actually stimulate creative problem solving and improved the situation for ad parties involved. Since conflict is seemingly unavoidable, it is obviously necessary for managers to be able to recognize the source of the conflict, and to view its constructive as well as destructive potential, to learn how to manage conflict and to implement conflict resolution technique in a practical way.

Following decades of studies and experiences, many scholars have changed their views concerning conflict. Even since a decade and half, conflict had being considered as having the potential for positive growth (Fleetwood, 1987). Three assumptions indicating the possible positive nature of conflict are that conflict is natural, based on real differences and necessary (Deetz \& Stevenson, 1986). The point of these assumptions is the belief that management of conflict serves as a useful conception of the process of conflict resolution. That conflict is good and necessary is suggestive that conflict can stimulate innovative thinking when properly managed.

\section{CAUSES OF CONFLICT IN ORGANIZATIONS}

The identified conflicts in an organizations range from employee's behavior to institutional culture, leadership management style, recruitment and placement system, employees harassment and external influences.

Complaints: According to Collins (2009) a complaint is an expression of divergence in opinion or the viewpoint between two parties reflecting one party's dissatisfaction. A complaints is a lower level of conflict.

Disputes: According to Collins (2009) disputes have their origins in disagreement between the individuals. This disagreement becomes a dispute when one or the other party cannot accommodate the consequences of the disagreement, and insists on having it resolved because the party feels interest are undermined when the disagreement remain unresolved. When the dispute is not resolved in due time, it degenerate into conflict.

Personal problems: If the employee has problems outside of the workplace, such as marital $\mathrm{r}$ parental issues, she may take them to work with her. Consequently, if she is short and withdrawn from her coworkers, and if they are ignorant about the causes of her behavior, they will assume that she has an issue with them.

\section{CLASSIFICATION OF CONFLICT}

There are different ideas and views from different scholars about forms of conflict in organization. Such as

a. Relationship Conflict: this occurs when there are interpersonal incompatibilities among group members, including personality clashes, tension, animosity and annoyance. This type of conflict produces negative individual emotions, such as anxiety, mistrust, frustration and fear of being rejected by other team members.

b. Task Conflicts: There are disagreements about the content of a task and work goals, such as distribution of resources, procedures, and interpretation of facts. 
c. Process Conflicts: This is a disagreement about how task should be accomplished, individuals responsibilities and delegation. Some other forms of conflicts are interpersonal conflicts, interpersonal conflict/intra group conflict inter departmental conflict and inter organizational conflict.

d. Intrapersonal Conflict: This type of conflict refers to the state of individual mind. It is important to note that such state of mind is largely dictated by circumstances around him. Such situations are anger, depression, confusion, frustration, which could lead to aggression, erratic behavior addiction and finally suicide Ross (1993). This is the kind of conflicts that has been described as "man against self".

e. Interpersonal Conflict: This is a conflict between two parties, in this case refers as "man against man". This type of conflict may be direct opposition as in exchange of blows, boxing, wrestling and gunfire it may be subtle conflict between the desires of two or more persons.

f. Man Against society - man against nature: This is one of the most interesting conflict Morel! (2009) posits that "man against society" type of conflict arises when man stands against a man-made institution or practices. These may include slavery, human trafficking, child prostitution, bullying, corruption and bad governance and so on so forth. Such conflict man against man" conflict may shade into man against society," man against nature, is the type of conflict that depicts a state of contention between man and his environment.

g. Family conflict: This type of conflict occurred in a family setting and also is described as intra-unit conflict. This conflict arise from crisis occasioned by family roles. Examples of these are father-son, mothers-father, husband-wife, brother-sister Conflict. Such conflict may be curse by factors like seniority claim, laziness, truancy at school, rudeness lying and sometimes cases like land, property and inheritance.

h. Inter Group Conflict: this refers to the kind of disagreement that takes place between two or more religious groups, ethnic groups, communities or interest groups. A good example of this type inter group conflict is that of Christians and Muslims in Nigeria. Inter-Community conflicts include Amichi and Utuh, Aguieri and Umuleri clashes.

\section{TYPES OF CONFLICTS:}

Whether a conflict is good or bad depends on the type of conflict. It is however good to differentiate between functional and dysfunctional conflicts.

Functional or Constructive conflicts: The interactions view does not propose that all conflicts are good. Rather, some conflicts support the goals of the group and improve its performance. The argument is that if conflict leads to normal competition among groups and the groups work harder and produce more, it is advantageous to the group and the institution. These are functional or constructive conflict.

Dysfunctional/Destructive Conflict: These are the conflict that hinder group performance, it can tear relationships apart and this interfere with the exchange of ideas, information and resources in group between departments. These types of conflict hinder and present the progress of organization which will lead to low productivity.

\section{CONCLUSION:}

Conflict in the organizations, societies and families are inherent because they are structured and main to produce conflict. The chapter has examined the classification, causes and types of conflict with their possible solutions and benefits. From this study, it is quite evidence that conflicts occurs in these various areas due to competition for supremacy, misunderstanding, truancy, leadership style and disrespect. This, early recognition of the conflict and paying attention to the conflicting parties is very important. Negotiation between parties involve is the best way to resolve conflict.

\section{RECOMMENDATIONS:}

1. Training workshops should be organized for staff of the organization on conflict resolution.

2. To management team, should learn how to delegate authorities to the low cadre.

3. All inclusive management style should be practice, rather than autocratic.

4. Working as a team should be encouraged rather competing for supremacy.

5. Staff welfare should be any management top priority in the organization. 


\section{REFERENCES}

1) Azamosa O. (2004) Industrial Conflict in Nigeria Universities: The case of the Academic Staff, Union of the University Teacher's Strike of December 2002 - June 2003

2) Obisi, C. (2003) Industrial Relations. Ibadan: Freeman production.

3) Schramm - Nielse, J. (2002) Conflict Management in Scandianvia, Department of International communication and Management Copehlangan Business School. Denmark.
4) Collins, S. D. (2009) Managing Conflict at Workplace, $2^{\text {nd }}$ Ed. South Western CENGAGE Learning, Series Editions

5) Morell, J. (2009). Thanks, but this isn't for us (London: Penguin) Ross, E.I (1993) Write Now (Barnes and Noble Publishing)

6) Deetz, Stanley A.R Sheny \& Stevenson (1986) Managing Interpersonal Communication New York. Herper.

7) Fleetwood, K .L. (1987) The Conflict Management Styles of strategies of Educational mangers. Unpublished Master's thesis. University of Delawore, Network.

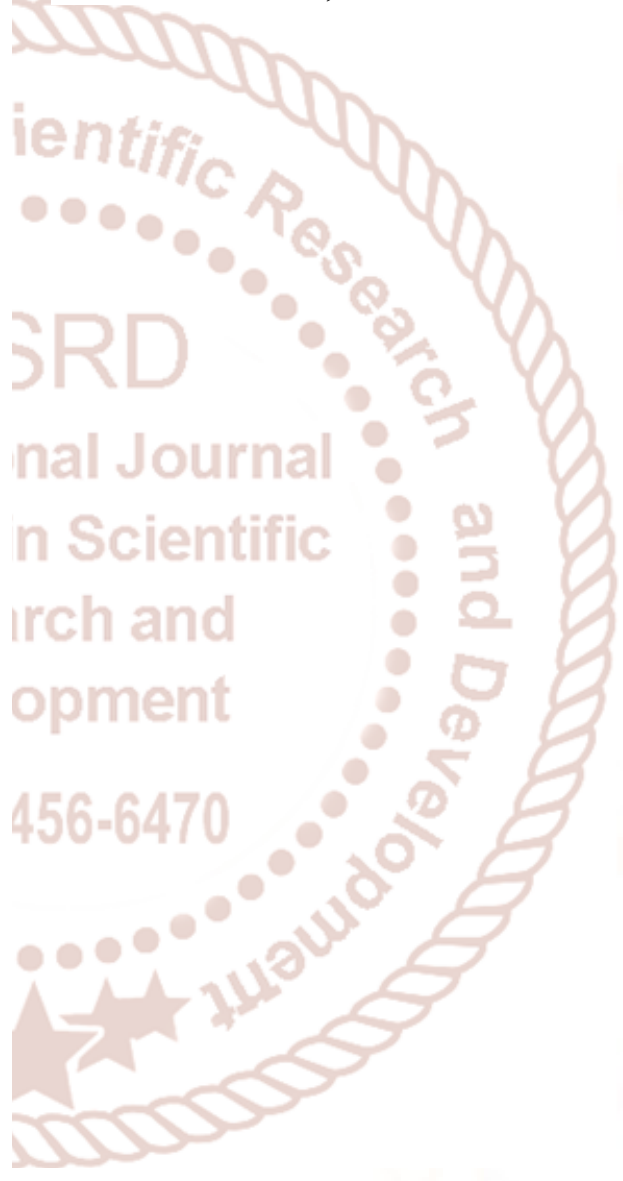

